comparison with behavioural changes in activity patterns and differences in fat deposition. We have measured both of these variables longitudinally, using the recently developed doubly labelled water $\left({ }^{2} \mathrm{H}_{2}{ }^{18} \mathrm{O}\right)$ method, which assesses body composition and total energy expenditure in free living subjects. ${ }^{+}$The high level of variability between subjects observed in the calorimetry study was equally apparent, and the total cost of pregnancy (computed as the cumulative change in total energy expenditure plus the energy deposited as fat and as the products of conception) averaged $532(254) \mathrm{MJ}(\mathrm{n}=7)$, with a range of $104-790 \mathrm{MJ}$ This average far exceeds the assumption of the World Health Organisation and the Food and Agricultural Organisation of $335 \mathrm{MJ}$ because the women chose to be more physically active during pregnancy. These results show that changes in energy expenditure associated with increased or reduced physical activity may easily exceed the physiological cost of pregnancy, and to meet these costs the women in this study must have substantially increased their food intake. With regard to this point, the introductory statement by the authors may need clarification. They point out, correctly, that a few studies have apparently shown little increase in food intake, but this is not the general rule. A review of 25 studies from affluent societies showed that pregnant women on average consume $1.0 \mathrm{MJ}$ more daily than non-pregnant women. ${ }^{2}$ The recorded intakes have been below internationally recommended levels not because there was no increase in intake during pregnancy but because the increase was added to a very low baseline intake caused by our modern, inactive lifestyle. ${ }^{5}$

A M Prentice

R G WHITEHEAD W A COWARD G R GOLDBERG H L DAVIES

Medical Research Counci

P R MURGATROYD

Dunn Nutrition Unit,

Cambridge CB4 1XJ

I Lawrence M, Lawrence F, Lamb WH, Whitehead RG. Maintenance energy cost of pregnancy in rural Gambian women and influence of dietary status. Lancet 1984;ii:363-5.

2 Prentice AM, Whitehead RG. The energetics of human reproduction: Symposia of the Zoological Society (London) 1987;57 275-304.

3 Goldberg GR, Prentice AM, Murgatroyd PR, Davies HL, Scot $W$. Individual variation in the energy cost of pregnancy. $1.24 \mathrm{~h}$ whole body calorimetry. Proc Nutr Soc (in press).

4 Davies HL, Prentice AM, Coward WA, et al. Individual variation in the energy cost of pregnancy. 2. Doubly labelled water method. Proc Nutr Soc (in press).

5 Prentice AM, Coward WA, Davies HL, et al. Unexpectedly low levels of energy expenditure in healthy women. Lancet 1985; i:1419-22.

\section{Standards for blood pressure measuring devices}

SIR,-The recent leading article by Dr E O'Brien and colleagues (16 May, p 1246) and ensuing correspondence ( 20 June, p 1614) regarding blood pressure measuring devices highlight the broader issues of standards of health equipment in general. The British Hypertension Society took the initiative in this case, presumably because effective standards were not available.

Health equipment now constitutes a multimillion pound market, and the problem of selecting the most cost effective products presents a dilemma for the budget conscious manager; clinician, or nurse. Detailed objective information is necessary to make an appropriate choice. The reports in Health Equipment Information are a step in the right direction, but such guidelines often arrive too late.

This is surely a matter for the National Health Service Management Board to review urgently.
Considerable savings might be achieved by more prudent selection and negotiation of contracts with manufacturers. Independent reports on the clinical and technological performance of equipment would be invaluable, and their preparation would require closer cooperation between clinical departments and the scientific and technical division of the Department of Health and Social Security. In theory, the health care standards committees of the British Standards Institution constitute the multidisciplinary executive forum to coordinate such trials, to identify the relevant specifications, and, finally, to produce the agreed standards.

A more critical approach to the cost effectiveness of health equipment, including the wide range of disposable products, might stimulate enterprising innovations among British manufacturers. We cannot but be aware of the increasing proportion of this industry that is under the control of foreign manufacturers.

Ham Green Hospital,

R C L FENELEY Bristol BS20 0HW

\section{Ruptured abdominal aortic aneurysm presenting with ureteric colic}

SIR,-It was with some chagrin that we read the article by Mr C G Moran and colleagues (16 May, p 1279) as we were preparing a similar article, based on two case reports, with a similar message. We still consider, however, that one of our cases merits attention, as the mistaken diagnosis of ureteric colic led to a delay that proved fatal.

A 46 year old man presented to the accident and emergency department complaining of a first attack of right sided loin pain. There was no relevant history, but he had been a heavy smoker for many years Physical examination yielded normal results; in particular, his abdomen was not tender and no masses were palpable and there was no evidence of arteria disease. An intravenous urogram was arranged, which proved to be normal, but he collapsed while it was being performed. At laparotomy an infrarenal abdominal aortic aneurysm was found, which had ruptured into the retroperitoneum. There was no evidence of ureteric involvement. Resuscitation and surgery were unsuccessful, and he died on the operating table.

Urèteric obstruction associated with inflammatory aneurysms of the aorta is well recognised. We agree with Mr Moran and colleagues that abdominal aortic aneurysm is rare, and ruptured aneurysm rarer still, in men under the age of 50 . The mortality from untreated rupture in the younger age group, however, is the same as that in older patients, and we suggest that the diagnosis should be borne in mind even in younger patients with severe abdominal pain. Ruptured aneurysms have presented mimicking almost every acute abdominal condition.

We also believe that the remark that "ultrasound is not available in the emergency room" should not be allowed to pass without comment. In our own hospital ultrasound is a readily available and much used investigation, and emergency ultrasound is easy to obtain. We find that urgent ultrasound of the abdomen is invaluable in the management of many of our emergency referrals and think that it should be more widely available.

Finally, it is unfortunate that in the issue that contains a plea for accuracy of references by Drs Evan Begg and Peter Moller (p 1291) Mr Moran and colleagues should state that "up to half of patients dying in hospital from ruptured abdominal aortic aneurysm do so without the diagnosis being made." McGregor's paper, ${ }^{1}$ to which this statement is attributed, dealt only with deaths from untreated rupture of abdominal aortic aneurysm, slightly over half of which were undiagnosed. We think we may assume that untreated cases represent a small subgroup of presenting cases and that the proportion of patients dying undiagnosed is therefore smaller.

J B ROUSSAK E R T C OWEN

Northwick Park Hospital,

Middlesex HAl 3UJ

1 McGregor JC. Unoperated ruptured abdominal aortic aneurysms: a retrospective clinicopathological study over a 10-year period. Brf Surg 1976;63:113-6.

\section{AIDS: a faltering step}

SIR,-We support the ethical opinions expressed by Professor Michael Adler and Dr D J Jeffries (11 July, p 73). Since, as doctors, we acquire any authority or right to treat or investigate patients only by their request (or that of their parent or legal guardian if they are at the time incapable) we cannot have any moral or legal right to carry out tests on them other than by their informed consent.

In certain urgent circumstances, however, consent may be taken to be implied. The fact that some investigations have, in the course of time, become routine (such as testing for syphilis in pregnancy) can be justified only on the basis that consent was implicit. With a disease of such prognostic importance and with such lethal implications as the acquired immune deficiency syndrome such a presumption cannot be justified, and fully informed consent should be obtained before any tests are performed.

Guild of Catholic Doctors,

I M JESSIMAN Kent BR7 5ES

SIR,-Infection with the human immunodeficiency virus (HIV) may cause psychosis ${ }^{1-3}$ and should be considered in the differential diagnosis of all patients from high risk groups (promiscuous patients, homosexuals, bisexuals, drug addicts, prostitutes, and haemophiliacs) who present with an abnormal mental state. A clinical dilemma is posed when such patients cannot give informed consent to testing for HIV (or understand the pretest counselling) because of their disturbed mental states.

In my personal experience with two psychotic patients who were HIV positive it was necessary to detain both under the Mental Health Act, as one had tried to throw himself in front of passing vehicles and the other had threatened to cut his mother's throat. ${ }^{12}$ There will doubtless be some psychotic patients (from high risk groups) who are, however, not thought to be a risk to themselves or others but who cannot give informed consent to testing for HIV, ${ }^{3}$ and it seems inappropriate to recommend detention of such patients under the Mental Health Act to perform a blood test. In such cases would a doctor be ethically justified in removing some blood from a cooperative patient for screening for HIV without obtaining informed consent?

University Hospital of South Manchester,

Christopher S Thomas Manchester M20 8LR

1 Thomas CS, Toone BK, El Komy A, Harwin B, Farthing CP. HTLV-III and psychiatric disturbance. Lancet 1985;ii:395-6. 2 Thomas CS, Szabadi E. Paranoid psychosis as the first presentation of a fulminating lethal case of AIDS. Br f Psychiatry (in press).

3 Rundell JR, Wise MG, Ursano RJ. Three cases of AIDS related psychiatric disorders. Am I Psychiatry 1986;143:777-8.

SIR,-There are many deplorable aspects of the recent vote by the BMA's annual representative meeting in favour of testing for human immuno- 